\title{
Usage-based Approaches to Second Language Acquisition: Cognitive and Social Aspects
}

\author{
Yaghoob Javadi \\ Department of Language Teaching and Translation, Varamin-Pishva Branch, Islamic Azad University, Varamin, Iran \\ Fakhereh Kazemirad \\ Department of Language Teaching and Translation, Varamin-Pishva Branch, Islamic Azad University, Varamin, Iran
}

\begin{abstract}
Usage-based approaches focus on learning language through engaging in the interpersonal communicative and cognitive processes. They consider language as the best accomplishment of our social and cognitive competences which bridges society and cognition. Based on usage-based approaches, language can be learned from language use, by means of social skills and generalizations over usage events in interaction. These approaches actually explore how language learning occurs through language experience. Therefore, usagebased approaches are input-dependent and experience-driven and assume frequency of usage as an inseparable part of language learning which plays an important role in the language production, language comprehension, and also grammaticality of the patterns. While usage-based approaches have been successful in showing how first language is learnt from the input, it is still less clear how these approaches can be made use of in second language learning. The present study provides an overview of the usage-based approaches to second language acquisition and their cognitive and social underpinnings. Firstly, the notion, underlying tenets, and major constructs of usage-based approaches are summarized. Then usage-based linguistics is described in detail. Finally, cognitive and social aspects of usage-based approaches are taken into account.
\end{abstract}

Index Terms - usage, usage-based approach, usage-based linguistics, second language acquisition

\section{INTRODUCTION}

"Language is learned in social interaction through shared experience and practice. This intuition has increasingly consolidated into a model of linguistic representation and language learning generally referred to as the usage-based theory" (Jing-Schmidt, 2018, p. 5). According to Wulff and Ellis (2018), 'Usage-based' is a label for various approaches to second language acquisition which minimally share two working hypotheses: first, the linguistic input language users receive is the main source for their second language learning; second, the cognitive mechanisms employed by language learners are not exclusive to only language learning, but are also associated with learning of any kind. Tan and Shojamanesh (2019) explain that the focus of usage-based approach is on cognitive linguistics which deals with the influence of input, experience, and frequency in language learning. In fact, usage-based approaches consider language as part of human cognition, and also as a meaning-making tool in a social context (Tomasello, 2003), which is essential for usage-based account of language learning. Usage-based approach of language learning which is an input-driven approach is in contrast to UG-based approach which claims that children have a prior language knowledge of grammar (Tan \& Shojamanesh, 2019). The usage-based approach became so popular that UG-based approach was assumed an outdated theory. This approach seeks to ground language structure in the usage-event which is the actual instances of language (Kemmer \& Barlow, 2000). In other words, "a usage-based model is one in which the speaker's linguistic system is fundamentally grounded in 'usage events' instances of a speaker's producing and understanding language" (Kemmer \& Barlow, 2000, p. iix). Similarly, Tomasello (2000) states that:

In usage-based models of language....all things flow from the actual usage events in which people communicate linguistically with one another. The linguistic skills that a person possesses at any given moment in time....result from her accumulated experience with language across the totality of usage events in her life...this theoretical freedom to identify these units on the basis of actual language use, rather than adult-based linguistic theory, is truly liberating. (p.61)

Langacker (1988) refers to three characteristics of usage-based model: maximalist, non-reductive, and bottom-up which are in contrast to generative traditions that are minimalist, reductive, and top-down. The first two characteristics imply the massiveness and redundancy of the grammar, and the third characteristic implies that general patterns emerge from specific patterns and these specific patterns are considered as the result of experience (Tan \& Shojamanesh, 2019). Vogt and Lieven (2010) argue that in usage-based approach, language is learnt through general pattern recognition mechanisms, which enable humans to construct their internal languages based on actual speech events. In fact, based on usage-based approaches of language acquisition, linguistic structures can be learned from language use and experience (Tomasello, 2003), by means of powerful generalization abilities (Behrens, 2009). According to Behrens (2009), learning grammar based on experience alone was long assumed to be impossible, but in recent years, advances in usage- 
based theory, developmental psychology, and computational linguistics changed the view on this matter. Behrens maintain that in usage-based approaches language can be learned through language use itself, by means of social skills and powerful generalization mechanisms. In addition, Kemmer and Barlow (2000) assert that since usage-based approaches are experience-driven, frequency of items is assumed as an inseparable part of language learning, especially in understanding structures and operations. Similarly, Tan and Shojamanesh (2019) state that frequency of usage in usage-based models plays an important role in the language production, language comprehension, and also grammaticality of the linguistic patterns. Therefore, usage-based theory does not rely on innateness for explaining linguistic categories and this is experience with language which influences its cognitive representation (Bybee, 2008).

\section{The Notion AND UndERLYING TENETS}

According to Behrens (2009), the term "usage-based" goes back to Langacker's (1987) assumption that a linguistic system is grounded in usage events or utterances. This term provides a helpful prism through which to regard linguistic models that emphasize language use as a primary shaper of linguistic form and also as the foundation for language learning (Tyler, 2010). "Originally, the notion of 'usage-based' was used to highlight a methodological and theoretical contrast between cognitive and generative linguistics” (Mengden \& Coussé, 2014, p. 2). Langacker (1987) distinguishes the concept of 'Cognitive Grammar' from 'Generative Grammar' and draws on the term 'usage-based' to endorse his claim that "irregular and idiosyncratic phenomena need to be accommodated into a convincing theory of language" (Mengden \& Coussé, 2014, p. 2). He believes that mental representations are grounded in usage rather than in an innate language faculty. Kemmer and Barlow (2000, pp. viii-xxii; cited in Mengden \& Coussé, 2014) list some key features of usage-based models:

- an intimate relation between linguistic structures and instances of use of language

- the importance of frequency

- comprehension and production as integral, rather than peripheral, to the linguistic system

- focus on the role of learning and experience in language acquisition

- linguistic representations as emergent, rather than as fixed entities

- importance of usage data in theory construction and description

- the intimate relation between usage, synchronic variation and diachronic change

- the interconnectedness of the linguistic system with non-linguistic cognitive systems

- the crucial role of context in the operation of the linguistic system

According to Tyler (2010), all usage-based approaches consider five key tenets: (a) The main purpose of language is communication which shapes language itself. (b) We always have natural language in context, and the user's utterances are influenced by contextual factors. (c) Language is learned and usage patterns including frequency information and collocational information are central to the learning of the system. (d) Grammatical patterns are assumed to be meaningful and meaning is not only related to lexical items. (e) Language can be fully and accurately accounted for and all syntactic patterns can be considered without assuming levels, such as deep or surface structure. Wulff and Ellis (2018) refer to another important tenet of usage-based approaches in the context of categorization, which is, there should not be any principled distinction between linguistic and other cognitive categories. This means that language users classify the world around them and the language that accompanies their experiences in the same way (Wulff \& Ellis, 2018). They maintain that since children's early competence is limited and no innate representations are regarded, language has to be learned through experience.

\section{Major Constructs of USAGE-BASEd ApProAches to SLA}

\section{A. Constructions}

The essential units of language representation are constructions which are pairings of form and meaning or function (Ellis \& Wulff, 2015). These form-function pairings are not restricted to the level of words and are assumed to pervade all layers of language. Simple words, simple morphemes, idiomatic expressions, and even abstract syntactic frames are constructions (Ellis \& Wulff, 2015). In other words, constructions differ in their degree of complexity and abstraction and range from simple morphemes to complex and abstract syntactic frames (Ellis \& Wulff, 2015). Shin (2017) states that "constructions are contained in a language user's lexicon and form structured inventories of the speaker's (grammatical) knowledge; and they are symbolic in that they blend morphosyntactic and lexical forms with semantic, pragmatic, and discourse functions associated with them" (p. 11).

\section{B. Associative Language Learning}

"Learning constructions means learning the association between form and meaning or function. The more reliable the association between a form and its meaning or function, the easier it is to learn" (Ellis \& Wulff, 2015, p. 75). Moreover, frequent constructions in the input are processed more readily than infrequent constructions. This fact implies that language is learned from usage and in an associative manner (Ellis \& Wulff, 2015). Experience makes a learner's perceptual system highly tuned to expect constructions based on their likelihood of occurrence in the input (Ellis \& Wulff, 2015). 


\section{Rational Cognitive Processing}

"Language learning is rational such that a learner's knowledge of a given form-meaning pair at any point in their language development is a reflection of how often and in what specific contexts the learner has encountered that formmeaning pair" (Ellis \& Wulff, 2015, p. 78). In fact, language users are assumed to be rational, because they have a mental model of their language which is custom-fit to their experience of language at any given time (Ellis, 2006; cited in Ellis \& Wulff, 2015). Their unconscious language systems can predict the constructions which are relevant to the ongoing discourse context, preparing them for both comprehension and production (Ellis \& Wulff, 2015).

\section{Exemplar-based Learning}

"The learner's brain engages simple learning mechanisms in distributional analyses of the exemplars of a given form-meaning pair that take various characteristics of the exemplar into consideration, including how frequent it is, what kind of words and phrases and larger contexts it occurs with, and so on" (Ellis \& Wulff, 2015, p. 76). Usage-based theories study how the acquisition of generative schema, productive patterns, and other rule-like regularities is based on exemplars (Ellis \& Wulff, 2015). Whenever the learner encounters an exemplar of a construction, the language system starts to compare this exemplar with previous encounters of the same or similar exemplar in order to retrieve the correct interpretation. Based on exemplar theory, constructions emerge over time as the learner's language system, and this system processes exemplar after exemplar, identifies the existing regularities and then makes the corresponding abstractions (Ellis \& Wulff, 2015).

\section{E. Emergent Relations and Patterns}

Language learning is assumed as a gradual process in which language emerges as a complex system from the interaction of cognitive learning mechanisms with the input (Ellis \& Wulff, 2015). Complex systems involve the interactions of different parts and share the key aspect that many of their systematicities are emergent, which means that they develop over time in complex, dynamic, and adaptive ways (Ellis \& Wulff, 2015). Language is considered as a complex adaptive system and comprises the interactions of people who want to communicate and also a world to be talked about. In addition, language operates across various levels, different human conglomerations and different timescales (Ellis \& Wulff, 2015).

\section{USAGE-BASED LINGUISTICS}

A usage-based linguistics is "a form of linguistic analysis, that is, that takes into account not just grammatical structure, but that sees this structure as arising from and interacting with actual language use (Geeraerts \& Cuyckens, 2007, p. 17; cited in Tan \& Shojamanesh, 2019). According to Diessel (2017), usage-based linguistics is in sharp contrast to the generative and structuralist approach in which the study of language system is considered to be separated from the study of language use. It rejects the innateness hypothesis of generative grammar and challenges the assumption that linguistic structures are built from a set of innate linguistic concepts (Diessel, 2017). Usage-based linguistics emphasizes language use as a main factor for shaping a language and assumes languages as dynamic systems that gradually emerge from learners' experiences with linguistic or non-linguistic input (Bybee \& McClelland, 2005; cited in Shin, 2017). Thus, Language acquisition becomes input-driven and sensitive to the experience of language use with other kinds of knowledge other than the language itself (Diessel, 2013, Ellis, 2006, Wulff, 2013; cited in Shin, 2017). The general purpose of usage-based linguistics is to develop a dynamic theory of language which accounts for the effects of cognitive and interactive processes on the emergence of meaning and structure (Diessel, 2017). Therefore, in usage-based linguistics, language is seen as a dynamic system of fluid constructions that are constantly restructured and reorganized under the influence of domain-general cognitive processes that are involved in language use (Diessel, 2017).

One important aspect of usage-based linguistics is frequency of occurrence (Diessel, 2017). According to Ellis (2002), the frequency of occurrence tunes acquisition and language processing because humans are born with a strong sense to recognize frequency distributions and their central tendencies. It is believed that frequency effects play an important role in language acquisition and help learners in acquiring lexical frames and extending those frames to generalized abstract representations in both L1 and L2 settings (Shin, 2017). In fact, frequency strengthens the representation of linguistic elements in memory and facilitates the processing and activation of words, categories, and constructions, which can have effects on the organization and development of linguistic system (Diessel, 2017). Another significant aspect of usage-based linguistics concerns the relationship between lexical and structural knowledge (Diessel, 2017). In usage-based linguistics, there is a close relationship between lexical and grammatical knowledge, because abstract representations of linguistic structure are derived from language users' experience with concrete linguistic tokens (Diessel, 2017). In other words, in the usage-based approach, in contrast to structuralist approach, linguistics structures are not independent of particular lexical expressions (Diessel, 2017). Thus, the usage-based linguistics relies on insights from cognitive linguistics, which is a nonmodular theory that assumes linguistic structure is dependent on the semantics and pragmatics it encodes (Behrens, 2009). 
Ellis (2020, p. 239) claims that usage-based linguistics explores how we learn language through experiencing it. He maintains that usage-based linguistics is founded upon findings from four complementary areas of empirical investigation:

1. Corpus linguistics demonstrates that language usage is pervaded by collocations and phraseological patterns, that every word has its own local grammar, and that particular language forms communicate particular functions: lexis, syntax, and semantics are inseparable.

2. Cognitive linguistics shows how language meaning is grounded in our experience and our physical embodiment which represents the world in particular ways. Language consists of many tens of thousands of constructions - form- meaning mappings, conventionalized in the speech community, and entrenched as language knowledge in the learner's mind. Schematic constructions emerge from the conspiracy of memories of particular exemplars that language users have experienced.

3. The psychology of learning shows that humans have a range of abilities for implicit associative and statistical learning, concept learning and categorization, and explicit declarative learning and analogy making. These are relevant to the learning of the symbols, sequences, and patterns of language that imbue our every waking moment.

4. Psycholinguistics shows that our language processing is sensitive to the statistical regularities of language experience at every level of structure.

\section{Cognitive Aspects of Learning a Language Through Usage-BASEd ApProaches}

Language is the best accomplishment of our social and cognitive competences and bridges society and cognition (Ellis, 2015; Ellis, R“omer, \& O’Donnell, 2016). Usage-based approaches investigate how we learn language while we are engaging in the interpersonal communicative and cognitive processes that shape language (Ellis et al., 2016). "Usage-based researchers acknowledge that language development is situated in a social context, with a learner's cognitive processes influenced by and responding to the characteristics of a given usage event" (Roehr-Brackin, 2015, p. 182). Thus, the social and cognitive-psychological are assumed as closely intertwined (Eskildsen 2009, 2012; Verspoor \& Behrens 2011; cited in Roehr-Brackin, 2015). According to Ellis (2015), language learning involves determining structures from usage and this involves the full scope of cognition: "the remembering of utterances and episodes, the categorization of experience, the determination of patterns among and between stimuli, the generalization of conceptual schema and prototypes from exemplars, and the use of cognitive models, metaphors, analogies, and images in thinking" (p. 49). Mengden and Coussé (2014) also claim that despite the prominence of 'usage' in usage-based approaches, these approaches essentially focus on cognition and present a cognition-centered perspective. Roehr-Brackin (2015) considers cognition as shared, embodied, and situated. She argues that cognitive functions occur in specific settings, which are viewed as a part of cognition. According to Bybee (2010, p. 2; cited in Ibbotson, 2013), usage-based approaches draw on several cognitive processes which have influence on the use and development of linguistic structures:

(i) categorization; identifying tokens as an instances of a particular type (ii) chunking; the formation of sequential units through repetition or practice (iii) rich memory; the storage of detailed information from experience (iv) analogy; mapping of an existing structural pattern on to a novel instance, and (v) cross-modal association; the cognitive capacity to link form and meaning.

Roehr-Brackin (2015) explains that in the usage-based approach, the processing and representation of language is understood in terms of domain-general cognitive mechanisms like categorization and entrenchment. Categorization refers to an individual's differential responses to events or objects in separate classes (Ashby \& O'Brien, 2005; cited in Roehr-Brackin, 2015). Entrenchment means to strengthen memory traces through repeated activation. Entrenched constructions are known as conventional linguistic units, which are considered as inherently symbolic, so constructions at different levels of abstraction are assumed as pairings of form and meaning (Goldberg 2003; cited in Roehr-Brackin, 2015).

Ellis (2015) describes some of the main cognitive linguistic tenets of construction grammar and usage-based approaches: a) "Language is intrinsically symbolic, constituted by a structured inventory of constructions as conventionalized form-meaning pairings used for communicative purposes" (Ellis, 2015, p. 50). b) Language is intrinsically linked to human cognition and also to processes of attention, perception, memory, learning, schematization, and categorization. c) Adult language knowledge includes a continuum of linguistic constructions of various levels of abstraction and complexity. "Constructions can comprise concrete and particular items, more abstract classes of items, or complex combinations of concrete and abstract pieces of language. It is believed that there is no rigid separation between grammar and lexis" (Ellis, 2015, p. 50). d) Constructions may be simultaneously stored and represented in multiple forms and at different levels of abstraction. e) Constructions can be meaningful linguistic symbols that exist independent from particular lexical items. Nevertheless, constructions and the particular lexical tokens are inseparable. f) Language structure emerges from usage in particular contexts which its development moves slowly and gradually from an initial reliance on concrete items to abstract linguistic schemata (Ellis, 2015).

To sum up, Mengden and Coussé (2014) assert that usage-based approaches make a cognitivist position plausible, in that they take into account the input and the circumstances of the speaker-hearer interaction in analyzing linguistic structures. Moreover, these approaches reveal the context-dependence of individual utterances and the conventional 
character of the system behind them as well (Mengden \& Coussé, 2014). Mengden and Coussé (2014) maintain that there must be something beyond the cognitive activity, which is vital for the nature of the linguistic systems, and these aspects are based on communication, or, more broadly, on the society.

\section{Social Aspects of LEARning a LANGUAge Through UsAge-BASED APPROACHES}

Language is considered as a social action and linguistic constructions would not work without social actions and vice versa (Eskildsen \& Cadierno, 2015). According to Eskildsen and Cadierno (2015, p. 10), “development of second language interactional competence also concerns a growing ability to control procedures or methods, including use of linguistic resources, for accomplishing social actions". For many second language learners, the target is not only to speak another language, but also to become part of the cultural and social environment in which this language is used. Ellis (2015) believes that the nature of language follows from the role it plays in social interaction. Social interactions are characterized by shared cooperative activity (Bratman 1992; cited in Ellis, 2015) or joint actions (Clark, 1996; cited in Ellis, 2015). Joint actions are dependent on shared cognition, which is a human being's recognition of being able to share intentions and beliefs with other human beings (Ellis, 2015; Ellis et al., 2016). Therefore, usage-based approaches put emphasis on how language is learned through participatory experience of language processing during embodied interaction in cultural and social contexts where individually desired outcomes are considered as goals to be achieved by communicating concepts, intentions, and meaning with others (Ellis, 2015; Ellis et al., 2016). Frith and Frith, (2010; cited in Ellis, 2015) state that in both neural activity and social world, the dynamics of language learning are linked to the dynamics of consciousness. Thus, consciousness is assumed to be co-constructed in social interaction (Ellis 2005) and the input to associative learning is considered to be socially gated (Kuhl 2007). According to Quine (1960; cited in Ellis, 2015), the robustness of language lies in the commonalities of its usage; this means that we learn language from other people, through the observable mouthing of words under obviously inter-subjective circumstances. "The uniformity that unites us in communication and belief is a uniformity of resultant patterns overlying a collective subjective diversity of connections between word and experience. Uniformity comes where it matters socially" (Quine, 1960, p. 8; cited in Ellis, 2015).

Therefore, shared cognition, shared cooperative activity, and shared attention are key to meaningful language usage (Ellis, 2015; Ellis et al., 2016). For second language acquisition, speakers, identity, speech and social relationships are inseparable. Lantolf and Thorne (2006; cited in Ellis, 2015) argue that socio-cultural approaches emphasize how language is learnt in social usage which involves action, reaction, intersubjectivity, collaborative interaction, and mutually assisted performance. Social-interactional approaches analyze how interaction provides reactive feedback and comprehensible, negotiated input (Gass 1997, 2002, 2003; Gass \& Mackey 2007; Long 1982; Mackey 2012; cited in Ellis, 2015). The kind of interaction that focuses participants' attention on resolving a communication problem and also the consequent negotiation of form and meaning can connect internal learner capacities, input, output, and selective attention in productive ways (Long 1996; cited in Ellis, 2015). Second language acquisition can be free from the limits of L1-induced selective attention by some means of form-focus which is socially given and socially determined and that recruits the learner's explicit processing (Ellis 2005). Bybee and Beckner (2010) state that usage-based approaches assume language as changing, dynamic and fluid through the interaction of social usage events with the cognitive processes' characteristics of the human brain. Cadierno and Eskildsen (2015), Atkinson (2016), and Hulstijn, Young, Ortega, Bigelow, DeKeyser, Ellis and Talmy (2014) marry the social aspect of usage-based approaches with the cognitive, in that so much of usage and attention in usage are socially driven (Wullf \& Ellis, 2018).

\section{CONCLUSION}

Usage-based approaches assume that all linguistic knowledge is constructed based on the input and the major part of language learning takes place implicitly and incidentally during meaning-focused input processing. These approaches are input-dependent and experience-driven and consider language learning as a complex adaptive system which involves multidimensional social and cognitive processes that interact in time and space. According to Ellis et al., (2016), work on usage-based approaches brings together people from different but complementary empirical and theoretical approaches, such as "cognitive linguistics, construction grammar, functional linguistics, cognitive psychology, learning theory, psycholinguistics, statistical learning theory, child language acquisition, neuroscience, corpus linguistics, computational science, natural language processing, emergentism, complex systems theory, conversational analysis, dynamic systems theory, sociolinguistics, and social learning theory" (p. 24). Thus, usagebased approaches to second language acquisition are gaining more currency in neighboring disciplines and the increasing integration of appropriate approaches and methodologies promises many interesting new perspectives for future research on the cognitive instantiation of language.

\section{REFERENCES}

[1] Behrens, H. (2009). Usage-based and emergentist approaches to language acquisition. Linguistics, 47 (2), 383-411. doi: 10.1515/LING.2009.014. 
[2] Bybee, J. \& Beckner, C. (2010). Usage-based theory. In B. Heine \& H. Narrog. (Eds.), The Oxford handbook of linguistic analysis (pp. 827-855). Oxford: Oxford University Press.

[3] Bybee, J. \& McClelland, J. (2005). Alternatives to the combinatorial paradigm of linguistic theory based on domain general principles of human cognition, The Linguistic Review, 22, 381-410.

[4] Bybee, J. (2008). Usage-based grammar and second language acquisition. In P. Robinson \& N. C. Ellis (Eds.), Handbook of cognitive linguistics and second language acquisition, (pp. 216-237). London: Routledge.

[5] Bybee, J. (2010). Language, usage and cognition. Cambridge: Cambridge University Press.

[6] Diessel, H. (2013). Construction grammar and first language acquisition. In G. Trousdale \& T. Hoffmann (Eds.), The Oxford handbook of Construction Grammar (pp. 347-364). Oxford: Oxford University Press.

[7] Diessel, H. (2017). Usage-based linguistics. In M. Aronoff (Ed.), Oxford research encyclopedia of linguistics. New York: Oxford University Press.

[8] Ellis, N. C. (2020). Usage-based theories of Construction Grammar: Triangulating Corpus Linguistics and Psycholinguistics. In Jesse Egbert \& Paul Baker (Eds.), Using Corpus Methods to Triangulate Linguistic Analysis (pp. 239-267). New York \& London: Routledge.

[9] Ellis, N. C. \& Wulff, S. (2015). Usage-based approaches to SLA. In B. VanPatten \& J. Williams (Eds.), Second language acquisition research series: Theories in second language acquisition (pp. 75-94). New York: Routledge.

[10] Ellis, N. C. (2002). Frequency effects in language processing: a review with implications for theories of implicit and explicit language acquisition, Stud. Second Language Acquisition, 24, 143-188.

[11] Ellis, N. C. (2005). At the interface: Dynamic interactions of explicit and implicit language knowledge. Studies in Second Language Acquisition, 27. 305-352.

[12] Ellis, N. C. (2006). Cognitive perspectives on SLA: the associative-cognitive CREED, AILA Review, 19 (1), 100-121.

[13] Ellis, N. C. (2015). Cognitive and Social Aspects of Learning from Usage. In T. Cadierno \& S. W. Eskildsen (Eds.), UsageBased Perspectives on Second Language Learning (pp. 49-73). Berlin: Mouton de Gruyter.

[14] Ellis, N. C. (2016). Cognition, corpora, and computing: Triangulating research in usage-based language learning. Language Learning, 67(S1), 40-56. doi: 10.1111/lang.12215.

[15] Ellis, N. C., R"omer, U. \& O’Donnell, M. B. (2016). Constructions and usage-based approaches to language acquisition. Language Learning, 66 (S1), 23-44. doi: 10.1111/lang.12177.

[16] Eskildsen, S. W. \& Cadierno, T. (2015). Advancing usage-based approaches to L2 studies. In T. Cadierno, \& S. W. Eskildsen (Eds.), Usage-based perspectives on second language learning (pp. 1-16). Berlin: Mouton de Gruyter.

[17] Eskildsen, S. W. (2009). Constructing another language: Usage-based linguistics in second language acquisition. Applied linguistics, 30 (3). 335-357.

[18] Eskildsen, S. W. (2012). L2 negation constructions at work. Language Learning, 62 (2). 335-372.

[19] Ibbotson, P. (2013). The scope of usage-based theory. Frontiersin psychology, 4 (255), 1-15. doi: 10.3389/fpsyg.2013.00255.

[20] Jing-Schmidt, Z. (2018). Computational and corpus methods for usage-based Chinese language learning: Toward a professional multilingualism. In: X. Lu \& B. Chen (eds) Computational and Corpus Approaches to Chinese Language Learning. Chinese Language Learning Sciences (pp. 13-31). Singapore: Springer. doi: 10.1007/978-981-13-3570-9_2.

[21] Kemmer S \& Barlow M. (2000). Introduction: A usage-based conception of language. In: M. Barlow, \& S. Kemmer (Eds.), Usage-Based Models of Language. Stanford, California: CSLI Publications.

[22] Kuhl, P. K. (2007). Is speech-learning gated by the 'social brain'? Developmental science, 10, 110-120.

[23] Langacker, R. W. (1987). Foundations of Cognitive Grammar: Theoretical Prerequisites. Stanford: Stanford University Press.

[24] Langacker, R. W. (1988). A usage-based model. In: B. Rudzka-Ostyn (Ed.), Topics in Cognitive Linguistics, 127-161

[25] Lantolf, J., \& Thorne, S. (2006). Sociocultural theory and the genesis of second language development. Oxford: Oxford University Press.

[26] Mengden, F. V. \& Coussé, E. (2014). The role of change in usage-based conceptions of language. In E. Coussé \& F. V. Mengden (Eds.), Usage-based approaches to language change (pp. 1-20). Amsterdam/ Philadelphia: John Benjamins.

[27] Roehr-Brackin, K. (2015). Long-term development in an instructed adult L2 learner: Usage-based and complexity theory applied. In T. Cadierno, \& S. W. Eskildsen (Eds.), Usage-based perspectives on second language learning (pp. 182-206). Berlin: Mouton de Gruyter.

[28] Shin, G.-H. (2017). Developmental aspects of English argument structure constructions for Korean-speaking second language learners: Usage-based constructional approaches to language development. Ampersand, 4, 10-20. doi: 10.1016/j.amper.2017.02.001.

[29] Tan, K. H. \& Shojamanesh, V. (2019). Usage-based and universal grammar-based approaches to second language acquisition. Psycholinguistics: Psychology of language use, learning and social interaction. doi: http://dx.doi.org/10.5772/intechopen.89737.

[30] Tomasello M. (2003). Constructing a language: A usage-based theory of language acquisition. Cambridge, MA: Harvard University Press.

[31] Tomasello, M. (2000). First steps toward a usage-based theory of language acquisition. Cognitive linguistics, 11, 61-82.

[32] Tyler, A. (2010). Usage-based approaches to language and their applications to second language learning. Annual Review of Applied Linguistics, 30, 270-291. doi:10.1017/S0267190510000140.

[33] Verspoor, M. \& Heike B. (2011). Dynamic systems theory and a usage-based approach to second language development. In M. H. Verspoor, K. de Bot \& W. Lowie (Eds.), A dynamic approach to second language development: Methods and techniques, 25-38. Amsterdam: John Benjamins.

[34] Vogt, P. \& Lieven, E. (2010). Verifying theories of language acquisition using computer models of language evolution. International society for adaptive behavior, 18(1), 21-35. doi: 10.1177/1059712309350970

[35] Wulff, S. (2013). Input matters: the processor as a statistician, linguist. Approaches Biling. 3 (3), 362-366. 
[36] Wullf, S. \& Ellis, N. C. (2018). Usage-based approaches to second language acquisition. In D. Miller, F. Bayram, J. Rothman, \& L. Serratrice (Eds.), Bilingual Cognition and Language: The state of the science across its subfields (pp. 37-56). Amsterdam \& Philadelphia: John Benjamins. doi: 10.1075/sibil.54.03wul.

Yaghoob Javadi is an assistant professor of Applied Linguistics at Department of Language Teaching and Translation Studies at Islamic Azad University, Varamin-Pishva branch, Iran where he teaches post-graduate courses including Second Language Acquisition Studies, Curriculum Planning, Computer Enhanced Language Learning, and Language, Culture and Identity. His current research interests include cultural and cognitive aspects of second language acquisition, identity, CALL, curriculum planning and teacher education.

Fakhereh Kazemirad is a $\mathrm{PhD}$ candidate in Teaching English as a Foreign Language at Islamic Azad University of VaraminPishva branch, Iran. She has been a university lecturer in Tehran, Iran since 2013, prior to which she has taught English at language institutions. 